\title{
Museus e escolas: parceria na efetivação de ações culturais para a formação de público consumidor de cultura
}

\section{Museums and schools: partnership in the effectiveness of cultural actions for the training of public consumer of culture}

Museos y escuelas: asociación en la efectiva de acciones culturales para la formación de público consumidor de cultura

Maria Christina Lima Félix Santos ${ }^{1}$ Heitor Romero Marques ${ }^{2}$ Maria Augusta Castilho ${ }^{3}$

${ }^{1}$ Doutoranda do Programa de Pós-graduação em Desenvolvimento LocalMestrado/Doutorado da Universidade Católica Dom Bosco (UCDB). Pedagoga e Mestre em Desenvolvimento Local. E-mail: mclfs@yahoo.com.br, Orcid: http://orcid.org/0000-0002-5849-1426.

${ }^{2}$ Doutor em Desenvolvimento Local pela Universidad Complutense de Madrid. Docente do Programa de Pós-Graduação em Desenvolvimento Local da Universidade Católica Dom Bosco (UCDB). E-mail: heitorma@ucdb.br. Orcid: http://orcid.org/0000-0003-0093-1617

${ }^{3}$ Doutora em História Social. Professora no Curso de Graduação de História e do Programa de Pós-graduação em Desenvolvimento Local da Universidade Católica Dom Bosco (UCDB). E-mail: maugusta@ucdb.br. Orcid: http://orcid.org/0000-0001-5235-3164 
Resumo: Este artigo apresenta uma reflexão acerca da origem do termo museu, suas implicações históricas, bem como a relação desse espaço cultural com a escola, apresentando o museu como local de integração com a cultura e com a memória. O artigo foi desenvolvido com base no método bibliográfico descritivo, pautado ainda no método dedutivo, com embasamento teórico em diversas fontes de consultas como: livros, artigos científicos, documentos, sites, para estabelecer a importância da relação do museu-escola para a construção do conceito de cultura. O texto apresenta uma reflexão contemporânea pontuando a escola como um espaço de educação formal, e os museus enquanto espaços educativos não formais. O artigo evidencia a relação de parceria entre os museus e as escolas, para a formação de público visitante dos museus e consequentemente de futuros consumidores de cultura.

Palavras-chave: museu; escola; visitantes; memória; preservação.

\begin{abstract}
This article presents a reflection about the origin of the term museum, its historical implications, as well as the relation of this cultural space with the school, presenting the museum as a place of integration with culture and memory. The article was developed based on the descriptive bibliographical method, based on the deductive method, with a theoretical basis in several sources of queries such as: books, scientific articles, documents, sites, to establish the importance of the relation of the school museum to the construction of the concept of culture. The text presents a contemporary reflection punctuating the school as a space of formal education and the museums as non formal educational spaces. The article highlights the relationship of partnership between museums and schools, for the training of visiting public of museums and consequently of future consumers of culture.
\end{abstract}

Keywords: museum; school; visitors; memory; preservation.

Resumen: Este artículo presenta una reflexión acerca del origen del término museo, sus implicaciones históricas, bien con la relación de ese espacio cultural con la escuela, presentando el museo como local de integración con la cultura y con la memoria. El artículo fue desarrollado con base en el método bibliográfico descriptivo, pautado aún en el método deductivo, con base teórica en diversas fuentes de consultas como: libros, artículos científicos, documentos, sitios, para establecer la importancia de la relación del museo-escuela para la construcción del edificio concepto de cultura. El texto presenta una reflexión contemporánea puntuando la escuela como un espacio de educación formal y los museos como espacios educativos no formales. El artículo evidencia la relación de asociación entre los museos y las escuelas, para la formación de público visitante de los museos y consecuentemente de futuros consumidores de cultura.

Palabras clave: museo; escuela; los visitantes; la memoria; preservación. 


\section{INTROODUÇÃO}

O presente artigo propõe uma reflexão a respeito da parceria entre museus e escola. Destaca-se que os museus, por desenvolverem uma ação educativa não-formal, complementam a formação do indivíduo na construção do conhecimento, além de esses espaços não-formais, como territórios prazerosos que são, valorizarem as emoções e motivações na prática educativa. O artigo salienta o papel das escolas na sensibilização do aluno para visitar espaços museais, em colaboração para a formação de um público consumidor de cultura, bem como a importância dos educadores de instituições escolares para planejarem ações educativas em conjunto com os setores educativos dos museus. Apresenta a contextualização histórica dos museus, desde a origem da Grécia Antiga, chegando à contemporaneidade, utilizando-se do método bibliográfico descritivo para ressaltar a relação do museu para a construção do conceito de cultura.

Analisa o marco legal dos museus, enfocando o Estatuto dos Museus (Lei n. 11.904) e o Plano Museológico, apresentado pelo Instituto Brasileiro de Museus (IBRAM). Dentro do aspecto do marco legal, relaciona a questão da pluralidade cultural preconizada nos parâmetros curriculares nacionais ao papel de formação educacional, quanto à perspectiva da educação formal, trabalhada nas escolas, quanto à educação não formal; que é o trabalho de educação patrimonial desenvolvido nos museus.

Ressalta o papel essencial dos museus, por intermédio das vozes de alguns autores: Paulo Freire, Hanah Arendth, Pierre Bourdeu, Ecléia Bosi, pontuando a importância dos museus para o fortalecimento do sentimento de pertença local e para a permanência da história e da memória. E, por fim, o artigo apresenta como proposta para os museus estarem a serviço da sociedade e do desenvolvimento local, sendo fontes de referência para a interpretação da história e de reflexão acerca das transformações sociais.

\section{CONTEXTUALIZAÇÃO HISTÓRICA}

A palavra museu teve origem na Grécia Antiga, derivada de Mouseion, termo que denominava o templo dedicado às musas, divindades menores do panteão grego e que eram ligadas a diferentes ramos da arte e da ciência, 
sendo filhas de Zeus com Mnemosine, deusa da memória (INSTITUTO DO PATRIMÔNIO HISTÓRICO E ARTíSTICO NACIONAL [IPHAN], 2006). A formação dos museus é também influenciada pela relação da humanidade com a memória e a história.

Suano (1986) assevera que, na sociedade, posteriormente o termo reaparece no Egito mousein, em Alexandria, mas, para referenciar o saber enciclopédico, contemplando também além das bibliotecas, anfiteatro, observatório e o jardim botânico. Com a evolução histórica, o termo museu passou a referenciar ao colecionismo, prazer em se acumular objetos e obras de arte e até mesmo a guarda de inúmeros textos para posterior edição. Com a dominação dos territórios por parte do Império Romano, a partir das conquistas por meio de guerras, a cultura dos vencidos era também apropriada pelo Império Romano, que levava ao seu espaço/ localidade elementos representativos e coleções da cultura dos povos dominados; assim o colecionismo era forma de demonstração de poder e triunfo.

Possas (2013, p. 166) ressalta que esses espaços serviam para a legitimação de "novos" cientistas, que escreviam e divulgavam seus esforços de estabelecimento de diferentes métodos de classificação, de descoberta muito mais vasta do que se podia supor antes.

Surgiam assim, por intermédio da prática, os gabinetes de curiosidades, que representavam a preocupação do homem com a memória histórica, pois este percebeu que seria impossível guardar na memória toda a variedade das obras divinas/naturais e da ação humana/tecnologia.

Na análise de Possas (2013, p. 151):

Os gabinetes, a princípio, revelam um caráter enciclopedista, uma tentativa de se ter ao alcance dos olhos, pelo menos, o que existe em lugares distantes e desconhecidos. Ainda não existe uma preocupação nítida com a classificação, a nomeação de tudo o que descortina diante desses homens. Antes de qualquer coisa trata-se de juntar, de colecionar objetos que dão a ideia da existência de 'outros'. O ato de colecionar transfigura-se em compreensão de tudo o que há no mundo.

Já a partir da Idade Média, a Igreja Católica apresentava-se como um dos principais colecionadores, e as igrejas, mosteiros e espaços religiosos 
Museus e escolas: parceria na efetivação de ações culturais para a formação de público consumidor de cultura

eram verdadeiros museus, com exposições de peças valiosas, doadas pelos fiéis em resposta de fé, as coleções cresciam por ocasião das Cruzadas (tropas ocidentais enviadas à Palestina para recuperarem a liberdade de acesso dos cristãos à Jerusalém).

Com o fortalecimento dos reinados após o movimento de Reforma e Contrarreforma, que diminuiu o poder da Igreja, houve a ascensão do movimento museal, conhecido como gabinete de curiosidades, pois, para expressar poder, os reinados compravam a produção de novos artistas e montavam salas de exposição de objetos expressivos, curiosos e observáveis.

Nessa breve análise introdutória da história dos museus, fica claro que os museus refletem as transformações humanas e, dessa forma, seus discursos e coleções irão pontuar os interesses e as práticas sociais que então em acontecimento.

O primeiro museu conhecido é o Ashmolean Museum, que, no ano de 1683, em Oxford, Reino Unido, surgiu com doações de Elias Ashmole, da coleção de John Tradescant.

Apesar de serem espaços abertos ao público, as visitas aos museus eram restritas, somente com a Revolução Francesa e seus ideais, o espaço museal passava a ser ponto de reflexão para a nova classe, a burguesia (IBRAM, 2014).

O segundo museu público é o Museu Britânico, de 1759, e o primeiro público na França é o Louvre, de 1793. No Brasil, o primeiro museu fundado foi em 1862, do Instituto Arqueológico Histórico e Geográfico Pernambucano; todos os outros museus brasileiros datam do século XX, e o mais importante pela qualidade de acervo é o Museu de Arte de São Paulo Assis Chateaubriand (MASP), de 1947.

Considerando a evolução da história dos museus, associada às transformações humanas, ressaltamos que as coleções museais passam a ser vistas como espelhos dos interesses e práticas sociais contemporâneas. Na atualidade, houve a criação do IBRAM, em 2009, com a assinatura da Lei n. 11.906. A nova autarquia vinculada ao Ministério da Cultura (MinC) sucedeu ao IPHAN nos direitos, deveres e obrigações relacionados aos museus federais. O IBRAM é responsável pela Política Nacional de Museus (PNM) e pela melhoria dos serviços do setor - aumento de visitação e arrecadação 
dos museus, fomento de políticas de aquisição e preservação de acervos e criação de ações integradas entre os museus brasileiros.

Com a sua criação, o IBRAM também estimulou a Política Nacional de Museus e investiu recursos públicos na reestruturação de diversos museus brasileiros; como o Museu Histórico Nacional, Museu Castro Maya, Museu da Inconfidência, dentre outros.

O IBRAM (s/d) tem como missão para 2018-2020: promover a valorização dos museus e do campo museal a fim de garantir o direito às memórias, o respeito à diversidade e a universalidade de acesso aos bens musealizados. E por visão para a mesma temporalidade: ser referência na gestão de políticas públicas e na geração e difusão de conhecimento para o campo museal. E enfoca três pilares básicos: o da preservação, da difusão e do acesso; o da sustentabilidade e o de geração e difusão do conhecimento.

Os museus brasileiros também integram o Sistema Brasileiro de Museus, que tem por finalidade facilitar o diálogo entre museus e instituições afins, objetivando a gestão integrada e o desenvolvimento dos museus, acervos e processos museológicos brasileiros. Por meio de ações de preservação: a semana nacional de museus, a primavera de museus e o dia nacional do museólogo, atividades que colaboram para a gestão cultural e preservação do patrimônio.

\section{MUSEU E CULTURA}

No universo da cultura, o museu reafirma-se com funções as mais diversas e envolventes. Uma vontade de permanência da memória seduz as pessoas e as conduz à procura de registros antigos e novos, levando-as ao campo dos museus, no qual as portas se abrem sempre mais. A museologia é hoje compartilhada como uma prática a serviço da vida. O museu é um espaço fascinante onde se descobre e se aprende, nele se amplia o conhecimento e se aprofunda a consciência da identidade, da solidariedade e da partilha.

Por meio dos museus, a vida social recupera a dimensão humana que se esvai na pressa da hora. As cidades encontram o espelho que lhes revele a face apagada no turbilhão do cotidiano. E cada pessoa acolhida por um museu acaba por saber mais de si mesma. 
Museus e escolas: parceria na efetivação de ações culturais para a formação de público consumidor de cultura

Partindo da análise mais poética para uma análise pautada no marco legal, temos o que preconiza a Lei n. 11.904, de 14 de janeiro de 2009, que instituiu o Estatuto de Museus:

Consideram-se museus, para os efeitos desta Lei, as instituições sem fins lucrativos que conservam, investigam, comunicam, interpretam e expõem, para fins de preservação, estudo, pesquisa, educação, contemplação e turismo, conjuntos e coleções de valor histórico, artístico, científico, técnico ou de qualquer outra natureza cultural, abertas ao público, a serviço da sociedade e de seu desenvolvimento. (BRASIL, 2009, s/p).

A formação dos museus é bastante influenciada pela relação da humanidade com a memória e a história. Castilho e Ferreira (2012, p. 31-2) afirmam que:

O museu retém o saber que os olhos deixam de observar no cotidiano, faz com que se possa lembrar o que está adormecido nas mentes e ainda nos devolve o cotidiano de povos que não existem mais, mas foram os construtores do presente e por isso não devem ser esquecidos.

Para Hellwig (2014), os museus são especialistas na recordação da memória, que estabelece um papel importante na construção do imaginário e da identidade de uma sociedade. De acordo com o Conselho Internacional de Museus (ICOM):

O museu é uma instituição permanente sem fins lucrativos, ao serviço da sociedade e do seu desenvolvimento, aberta ao público e que promove pesquisas relativas aos testemunhos materiais do homem e do seu ambiente, adquire-os, conserva-os, comunica-os e expõe-nos para estudo, educação e prazer. (DESVALLÉES; MAIRESSE, 2013, p. 64).

Para Noronha (2010, s/p), no pressuposto do seu desenvolvimento, Museu de Arte Contemporânea firma-se

[...] durante o século XX, concomitante ao desenvolvimento das investigações museológicas e ao estabelecimento da Museologia enquanto disciplina. Algumas consequências: a possibilidade do Museu de Arte Contemporânea ser apresentado e apresentar-se como uma instituição que se estabelece em um contexto cultural, político e econômico e que está sujeita a redefinições conforme os interesses e mudanças desse próprio contexto. Se os primeiros cento e cinquenta anos do 
Museu de Arte Contemporânea foram marcados por um processo de institucionalização, ou seja, de incorporação e acumulação de um conjunto de conquistas históricas, normas e valores que tendiam a gerar as condições de sua própria reprodução (Bourdieu, 1989: 100), os últimos cinquenta anos foram marcados por um processo de reflexividade, ou seja, de pôr em causa de modo radical suas próprias práticas e seus próprios instrumentos de consolidação, abrindo-se a ações que tensionam o lugar privilegiado que seu discurso ocupa no contexto político e sociocultural em que se insere.

O IBRAM estabelece como princípios fundamentais dos museus, na Lei n. 11.904, de 14 de janeiro de 2009, Estatuto dos Museus, em seu Art. 2ㅇ, que os museus devem buscar:

I- a valorização da dignidade humana;

II- a promoção da cidadania

III- o cumprimento da função social;

IV - a valorização e preservação do patrimônio cultural e ambiental;

V- a universalidade do acesso, o respeito e a valorização à diversidade cultural;

VI- o intercâmbio institucional.

Os museus adquirem, por intermédio das práticas educativas não formais, força e visibilidade, passando a ser visto como espaço para a disseminação do conhecimento e formação. Também estabelece a legislação que os museus deverão promover ações educativas, fundamentadas no respeito à diversidade cultural e na participação comunitária, contribuindo para ampliar o acesso da sociedade às manifestações culturais e ao patrimônio material e imaterial da Nação. Ressaltamos que o tripé da identidade de um museu, que consiste em: ter sua coleção organizada, de ser esta de acesso ao público e de proporcionar ações educativas, precisa existir de fato, para justificar o espaço como um museu.

As atividades basilares de um museu devem ser voltadas para a preservação, para a pesquisa e para as diversas formas de comunicação com a sociedade. Com um plano de trabalho atrelado à questão social, o papel educativo não formal dos museus garante-se formalmente, e hoje não há a política do gabinete de curiosidades, ou seja, exclusivamente de visitações e verificação de coleções. 
Museus e escolas: parceria na efetivação de ações culturais para a formação de público consumidor de cultura

Muito além de casas de memória, os museus constituem em casas da vida de um país, marcas da formação de seu território. São espaços, construtos que assumem cada vez mais sua função junto ao povo e, conforme preconiza o IBRAM, são casas de conhecimento, vivência e transformação. Não se pode analisar a essência de um museu sem estabelecer uma reflexão acerca da importância da memória na preservação desses espaços culturais.

Le Goff (1996) assevera que a memória é a propriedade de conservar certas informações, propriedade que se refere a um conjunto de funções psíquicas que permitem ao indivíduo atualizar impressões ou informações passadas, ou reinterpretadas como passadas. Assim a memória se alicerça aos fundamentos da História, confundindo-se muitas e tantas vezes com o documento, com o monumento e com a oralidade.

De acordo com Todorov (2002, p. 141), "a memória é a vida do passado no presente", ou seja, é a memória que nos permite conhecer as permanências e compreender as transformações.

Fernandes (2009) afirma que a preservação da memória cultural visa à continuidade das manifestações culturais de uma determinada comunidade e é essa a verdadeira responsável e guardiã de seus valores culturais.

Todas essas lembranças, histórias e memórias são hoje relatadas aos mais novos por meio da história oral, e, quando falamos de história oral, vemos que esse é um processo de recordação construtivo e que depende da situação presente: "na maior parte das vezes, lembrar não é reviver, mas refazer, reconstruir e repensar as imagens de hoje, as experiências do passado" (BOSI, 1994, p. 55).

As narrativas contribuem para a composição de imagens da história passada àqueles que não viveram os fatos. Nesse enfoque, Fonseca (1997, p. 34) destaca que "o registro das histórias permite uma compreensão do modo de ser do indivíduo e do contexto social, de sua profissão, não como realmente existiu, mas como esses próprios sujeitos reconstroem suas experiências passadas".

"A memória poderá ser conservação ou elaboração do passado [...]" (BOSI, 1994, p. 68). Refletindo a respeito da teoria de Bosi (1994), é possível crer que, por meio da memória, não importando seu caráter individual ou coletivo, é possível a uma comunidade proteger sua história, conhecendo 
o passado para constantemente reconstruir o presente com base nas experiências pregressas.

Relacionando memória a preservação, ressaltam-se com atividades basilares de um museu: a preservação da história, a oportunidade de pesquisa e as diversas formas de comunicação com a sociedade.

Para o Instituto Brasileiro de Museus (IBRAM, 2014, p. 23):

Os processos de comunicação museológica, se abertos, multidirecionados e participativos, são caminhos para o desenvolvimento da capacidade crítica e cognitiva dos indivíduos. Usando variados modos de leitura dos discursos expositivos e com uma comunicação dialógica entre os museus e a comunidade, é possível criar novos laços, incentivar a autonomia e o empoderamento. É possível também ampliar as maneiras de perceber e estar no mundo - tanto das pessoas quanto dos museus".

A relação do museu com o visitante é um processo dialógico, pois os dois lados aprendem e ensinam, ambos se modificam e saem diferentes do que eram. Para Paulo Freire (2002), em sua obra Pedagogia do oprimido, destaca a necessidade da educação problematizadora superar a contradição entre o educador e o educando: "ninguém educa ninguém, ninguém educa a si mesmo, os homens se educam entre si, mediatizados pelo mundo" (FREIRE, 2002, p. 68).

As ações de comunicação em museus ocorrem de múltiplas formas e devem priorizar a pesquisa e divulgação do acesso, a realização de exposições, as atividades de educação patrimonial e os eventos culturais, aproximam o fazer museal às mais diversas formas de expressão das artes.

Para que os museus tenham uma política de formação de público, suas atividades devem ser sistematizadas em programas. Na análise de Mário de Andrade, "o verdadeiro museu não ensina a repetir o passado, porém a retirar dele tudo o quanto ele nos dá dinamicamente para avançar em cultura dentro de nós, e em transformação dentro do progresso social" (ANDRADE, 1938 apud LOURENÇO, 2002, p. 188).

Museus são espaços de memória, identidade, conhecimento e turismo, assim locais para ação educativa não formal de visitantes locais e de turistas. Os museus podem servir ao turismo, são atrativos capazes de motivar o deslocamento de pessoas para conhecê-los. Porém, o grau de 
atratitividade do museu depende de seu formato/expografia, acervo, facilidade de acesso, enfim oportunidade ao visitante. Uma forma de expandir o fluxo de visitantes museais é realizar um bom plano de ação, atraindo, motivando, sensibilizando os turistas, fazendo-os terem prazer ao percorrer o território museal.

Os museus podem atuar como agentes de desenvolvimento local, dinamizando a cultura e a economia locais, com ações de economia criativa, como cursos de artesanato, estimulando as potencialidades do local, gerando emprego e renda.

\section{A ESCOLA E SEU PAPEL DE EDUCAÇÃO FORMAL}

Os acervos dos museus são variados por meio de múltiplos objetos e de seus espaços.

A expografia museal conta sua história, expõe uma narrativa. As narrativas museais são instrumentos de estudo, fontes de conhecimento a serem exploradas pelas escolas.

De acordo com o que se pretende estudar, cabe à escola, aliar em seu plano educativo as visitas aos museus; conforme a tipologia museal estabelece-se o recorte, a área de pesquisa: museus de arte, de arqueologia, enfim inúmeros territórios abertos à formação cultural e ao repasse de múltiplos saberes.

Os museus ampliam o acesso e a apropriação de bens artísticos e culturais, e a escola reorganiza os conceitos apresentados de modo informal em museus para fechar lacunas da história não contada.

Conforme o Estatuto dos Museus (BRASIL, 2009), os princípios fundamentais desses espaços culturais são:

1. Prezar pela valorização da dignidade humana;

2. Enfatizar a função social dos espaços museais;

3. Zelar pela preservação do patrimônio cultural e ambiental;

4. Oportunizar a universalização do acesso;

5. Respeitar a diversidade.

De acordo com o documento Museu e Turismo, o Instituto Brasileiro de Museus (IBRAM, 2014) destaca que: 
Os processos de comunicação museológica, se abertos, multidirecionados e participativos, são caminhos para o desenvolvimento da capacidade crítica e cognitiva dos indivíduos. Usando variados modos de leitura dos discursos expositivos e com uma comunicação dialógica entre museus e a comunidade, é possível criar novos laços, incentivar a autonomia e o empoderamento. É possível também ampliar as maneiras de perceber e estar no mundo - tanto das pessoas, quanto do museu.

A relação do museu com o visitante é um processo dialógico - pois ambos aprendem e ensinam e se modificam.

Paulo Freire $(1979 ;$ 2002) ressalta a importância e a necessidade de se entender a existência humana a partir de sua substancialidade, ou seja, o reconhecimento de todos os homens como verdadeiros sujeitos históricos. Os atributos dados aos seres humanos não podem, assim, sobrepujar o dado mais importante da existência humana: a sua presença no mundo como sujeito.

São múltiplas as capacidades e possibilidades da participação dos museus para um enriquecimento geral na aprendizagem/conhecimento, na qualidade de vida, na formação da consciência política e social da população, ou seja, o projeto político pedagógico da área educativa de um museal relaciona-se com o desenvolvimento local, pois promover o desenvolvimento local é permitir a participação do indivíduo na construção de sua história, por intermédio da inclusão social e da mobilização.

Os museus são definidos como espaços de educação não formal, assim possuem a responsabilidade de motivar a reflexão crítica a respeito das transformações sociais, considerando que normalmente a temática museal se relaciona à contemporaneidade. O museu educa sem ter um currículo pré-determinado, porém segue seu plano intencional, logo se assemelha ao ato formal educativo. Cabe ao mediador cultural, atuante em museus, o papel de favorecer um processo dialógico, entre os objetos, da exposição e os visitantes.

Cabe à escola que exerce a função educativa formal, a responsabilidade para com a formação cultural do educando, considerando o que estabelecem os Parâmetros Curriculares Nacionais, no que tange à pluralidade cultural. Na introdução da publicação dos PCN'S é estabelecido que: 
A temática da Pluralidade Cultural diz respeito ao conhecimento e à valorização de características étnicas e culturais dos diferentes grupos sociais que convivem no território nacional, às desigualdades socioeconômicas e à crítica às relações sociais discriminatórias e excludentes que permeiam a sociedade brasileira, oferecendo ao aluno a possibilidade de conhecer o Brasil como um país complexo, multifacetado e algumas vezes paradoxal. (BRASIL, 1997, p. 19).

Cabe à escola o compromisso de colaborar para a formação de cidadãos atuantes que cooperem para a preservação do patrimônio cultural. É importante a participação da escola na formação cultural, no sentido de suscitar também o hábito de seus educandos serem visitantes de museus, complementando ou assumindo o papel muitas vezes deixado de lado pela família.

\section{O MUSEU E A FORMAÇÃO EDUCATIVA NÃO FORMAL}

É importante entendermos o papel do museu na formação da aprendizagem, da informação e da ação interdisciplinar, sendo primordial reconhecer que existem diferenças entre cada tipo de educação em função de seus espaços culturais e físicos. É essencial reconhecer a diversidade e amplitude de atuação da sociedade e do pedagogo, em especial, daqueles que atuam em um espaço museal ou em uma escola.

Os educadores e pedagogos museais atuam de modo interdisciplinar, planejando em equipe as ações culturais, a serem desenvolvidas, objetivando conduzir o aluno-visitante a se apropriar do conteúdo do objeto ou obra exposta e da proposta do artista, inclusive oferecendo oficinas pedagógicas e momentos de contato direto com o artista, em que os alunos/escolas interpelam o autor acerca de suas obras, numa vertente sociocultural.

Os museus são importantes centros de conhecimento, espaços de memória e cultura, aspectos essenciais na construção dos saberes locais. Padilha, Café e Silva (2014, p. 71) destacam que:

No que diz respeito à cultura e às novas tecnologias, surge a necessidade de reflexão acerca de como as instituições museológicas, espaços de reflexão acerca de como as instituições museológicas, espaços de memória e cultura, desde sua formação até a atualidade, vêm contribuindo para a difusão do conhecimento contido nesse espaço físico. Para atender às novas exigências e necessidades dessa 
sociedade da informação/conhecimento que se apresenta, é preciso pensar na lógica dessas informações de cunho histórico, político, científico, social e cultural.

O grande desafio dos museus na contemporaneidade é o de voltar-se para ações de formação de público, compondo estratégias junto aos visitantes, principalmente às escolas, para incentivar a frequência e oportunizar situações para futuros consumidores e apreciadores da cultura e da arte.

As instituições museais podem agregar valor ao local/território em que se encontram promovendo ações culturais atrativas aos moradores da região, as quais servirão para reflexão e capilarização de ideias. No aporte de Meneses (1994), todos os museus são históricos, é claro. Dito de outra forma, o museu tanto pode operar as dimensões de espaço quanto de tempo. No entanto o tempo nunca poderá ser esquecido, essencialmente quando se procura contextualizar uma exposição.

Os museus promovem ações educativas não formais oportunizando à população local reconhecer esse território como local de interação cultural e permanência da memória. O plano de trabalho do setor educativo dos museus oferece ações aos visitantes, em que esses experimentam a ambiência da expografia museal, interagem com as coleções museais e absorvem o objetivo, a essência da exposição na construção da história e na permanência da memória.

Os museus podem trabalhar em conjunto com as escolas, motivando potencialidades, visando suscitar no indivíduo características endógenas culturais, considerando que o espaço museal gera novos saberes, reaviva a memória e coopera para a permanência da história em épocas vindouras, ou seja, é instrumento de preservação do patrimônio, para o futuro.

A relação museu-escola é importante para fazer com que os museus sejam redescobertos como espaços privilegiados de saber e de encontros sociais.

Na visão de Lopes (1991), não se trata, porém, de promover a "escolarização" do museu, mas de estudar a sua multiplicidade de papéis educativos que podem ser assimilados pelo espaço museológico.

Marandino (2001) pondera que os objetos museais sejam de categoria natural, técnica ou artística, podem construir fontes de prazer estético, de 
Museus e escolas: parceria na efetivação de ações culturais para a formação de público

deleite ou de observação científica. Os cenários e as animações presentes nas coleções ressaltam a força do objeto e podem aumentar o prazer da visita.

Tanto as escolas quanto os museus constroem plano de transmissão do saber cultural representativo de uma determinada época. Para o desenvolvimento do processo de aprendizagem, o objeto museal tem papel importante, pois esse elemento é comum no museu e na escola, sendo o objeto construto na referência de aprendizagem. Em museus os objetos são fontes de memória, já na escola são instrumentos de pesquisa.

Canclini (1998) afirma que o museu e a política patrimonial tratam os objetos, os edifícios e os costumes de tal modo que, mais que exibi-los, tornam inteligíveis as relações entre eles, propõem hipóteses sobre o que significam.

A exposição motiva o visitante do museu a realizar uma interpretação do espaço, uma releitura, interpretando o fato apresentado e compreendendo as nuances do contexto histórico.

O conhecimento e a apropriação do saber ocorrem por intermédio de narrativas, conduzidas pela organização dos objetos. Ramos (2004) propõe a reconfiguração dos objetos a partir do contexto museal. Ao tornar-se peça de museu o objeto passa por uma reconfiguração de sentidos.

Ninguém vai a uma exposição de relógios antigos para saber as horas. Ao entrar no espaço expositivo, o objeto perde o seu valor de uso: a cadeira não serve de assento, assim como a arma de fogo abandona sua condição utilitária. Quando perdem suas funções originais, as vidas que tinham no mundo fora do museu, tais objetos passam a ter outros valores, regidos pelos mais variados interesses. (RAMOS, 2004, p. 19).

A educação constrói o futuro das pessoas e da sociedade, enquanto geradora de avanços e prosperidade da comunidade. Conforme Hannah Arendt (2011), é essencial a educação numa perspectiva reflexiva da realidade e da participação comunitária:

A educação é, também, onde [o meio pelo qual] decidimos se amamos nossas crianças o bastante para não expulsá-la de nosso mundo e abandoná-las a seus próprios recursos, e tampouco arrancar de suas mãos a oportunidade de empreender alguma coisa nova e imprevista para nós, preparando-as em vez disso com antecedência para a tarefa de renovar um mundo comum. (ARENDT, 2011, p. 247). 
Quando se observa a relação museu-escola na cooperação para a formação de público apreciador de cultura, pontua-se a gama de responsabilidade de cada uma das instituições. Em sua obra $O$ amor pela arte, Bourdieu (2016) ressalta que os museus abrigam tesouros, que se encontram simultaneamente abertos a todos, embora fechados à população. Esse paradoxo aparece em todos os países pesquisados, demonstrando que a frequência de visitantes museais aumenta de acordo com que se amplia o nível de instrução dos frequentadores pesquisados.

Marandino (2001) demonstra a relação museu-escola por meio de um quadro sintético que pontua que os dois elementos são universos particulares, porém, complementares, em que as relações sociais se processam de forma diferenciada, cada um com uma lógica própria (Quadro 1).

Quadro 1 - Relação museu-escola

\begin{tabular}{|l|l|}
\hline Escola & Museu \\
\hline Objeto: instruir e educar & $\begin{array}{l}\text { Objeto: recolher, conservar, estudar e } \\
\text { expor }\end{array}$ \\
\hline Cliente cativo e estável & Cliente livre e passageiro \\
\hline $\begin{array}{l}\text { Cliente estruturado em função de ida- } \\
\text { de ou da formação }\end{array}$ & $\begin{array}{l}\text { Todos os grupos de idade sem distin- } \\
\text { ção de formação }\end{array}$ \\
\hline $\begin{array}{l}\text { Possui um programa que Ihe é impos- } \\
\text { to, pode fazer diferentes interpreta- } \\
\text { ções, mas é fiel a ele }\end{array}$ & $\begin{array}{l}\text { Possui exposições próprias ou itineran- } \\
\text { tes e realiza as suas atividades pedagó- } \\
\text { gicas em função de sua coleção }\end{array}$ \\
\hline $\begin{array}{l}\text { Concebida para atividades em grupo } \\
\text { (classes) }\end{array}$ & $\begin{array}{l}\text { Concebido para atividades geralmente } \\
\text { individuais ou de pequenos grupos }\end{array}$ \\
\hline Tempo: 1 ano & Tempo: 1 h ou $2 \mathrm{~h}$ \\
\hline Atividade fundada no livro e na palavra & Atividade fundada no objeto \\
\hline
\end{tabular}
Fonte: Marandino (2001).

Grinspun (2002) identificou que, no Brasil (São Paulo), é baixa a frequência de visitantes aos museus, e que as famílias não veem os museus como local para visitas em suas horas de folga, em sua pesquisa qualitativa, obteve como resultado, de que as famílias brasileiras têm como local para visitas em primeiro lugar os shoppings centers, seja de quaisquer classes sociais, em que as famílias de baixa renda vão com seus filhos, para passear e ver vitrines, e as famílias de classe mais elevada levam os filhos, para consumir os produtos. 
Museus e escolas: parceria na efetivação de ações culturais para a formação de público consumidor de cultura

Visto isso, os museus podem colaborar na ampliação do direito à cultura, e consequentemente na preservação do patrimônio cultural, sensibilizando os educadores e motivando os visitantes a utilizarem o espaço museal em suas horas de lazer.

O processo ensino-aprendizagem é fundamental na construção de hábitos culturais saudáveis. Paulo Freire (2000, p. 67) afirma que "[...] se a educação não muda o mundo, tampouco sem ela o mundo muda". Cabe aos educadores oportunizarem situação pedagógica para que a comunidade escolar perceba o mundo em que vive.

Com a cooperação museu-escola, há investimento na formação de futuros produtores e consumidores de cultura, pois hábitos e habilidades afloram na tenra idade, pois "uma criança satisfeita quer dizer uma família satisfeita; ela possivelmente será também um futuro adulto visitante, eventualmente, um pai/mãe amigo(a) dos museus" (IBRAM, 2014, p.43).

Para reverter a insipiente visitação aos museus brasileiros, esses espaços culturais, tão sucateados, os museus na grande maioria almejam a formação ideal de suas equipes, com o número de profissionais/formação necessário, pontuam ainda a necessidade de adequação de seus espaços físicos e a carência de recursos/investimentos financeiros. Esses são os principais problemas que impedem que os museus oportunizem condições apropriadas para o atendimento ao público e para que haja a expansão da cultura.

\section{CONSIDERAÇÕES FINAIS}

É importante o papel dos museus na permanência do patrimônio cultural, e para tal, a escola, com sua característica de educação-formal, deveria ter participação crucial na sensibilização dos educandos para com o espaço museal. Os museus atraem os visitantes locais e os turistas por conterem parte da história local e por participarem por intermédio de sua expografia da construção social, sendo instrumento essencial para a permanência cultura e da identidade local.

A relação entre museus e desenvolvimento local é percebida por meio dos pilares basilares dos museus, que são a preservação, a pesquisa e as diversas formas de comunicação com a sociedade. As exposições museais 
favorecem ao visitante, seja ele um turista ou um aluno, fazer uma leitura social e perceber a relação da história contada pelos objetos com sua própria história.

As escolas e os museus são duas das instituições mais antigas de nossa sociedade. A escola com uma política de educação formal e o museu com o papel de construtor de uma educação não formal. A escola brasileira, em pleno século XXI, enquanto instituição enfrenta muitos desafios tanto na área pedagógica quanto estrutural e, para atenuar os principais entraves que são o alto índice de reprovação, a evasão escolar e a formação deficitária dos professores, pode contar com a educação não formal para motivar os educandos e os educadores a novas perspectivas.

A escola é essencial na formação do indivíduo, porém não é o único espaço destinado à formação, existem os espaços não-formais que completam a tarefa educativa. A educação não formal ocorre fora da escola em ONGs, praças, parques, centros culturais, igrejas, museus e demais espaços. Locais em que se adquire conhecimento por intermédio de suas próprias experiências.

Os museus são espaços sociais que têm por funções básicas: promover a preservação dos bens culturais, a análise e a promoção dos bens patrimoniais. E, quando os museus e centros culturais desenvolvem ações em cooperação, a comunidade escolar caminha para a formação de hábitos culturais, fazendo dos alunos, futuros consumidores da cultura.

\section{REFERÊNCIAS}

ARENDT, Hannah. A crise na educação. [Ensaio]. In: ARENDT, Hannah. Entre o passado e o futuro. 7. ed. São Paulo: Perspectiva, 2011.

BOURDIEU, Pierre. O amor pela arte. Porto Alegre: Zouk, 2016.

BOSI, Ecléa. Memória e sociedade: lembranças de velhos. São Paulo: Companhia das Letras, 1994.

BRASIL. Lei n. 11.904, de 14 de janeiro de 2009. Institui o Estatuto de Museus e dá outras providências. Diário Oficial da União, Brasília 15 jan. 2009.

BRASIL. Secretaria de Educação Fundamental. Parâmetros curriculares nacionais: pluralidade cultural, orientação sexual. Brasília: MEC/SEF, 1997. 
Museus e escolas: parceria na efetivação de ações culturais para a formação de público consumidor de cultura

CANCLINI, Nestor. Culturas híbridas: estratégias para entrar e sair da modernidade. 2. ed. São Paulo: Edusp, 1998.

CASTILHO, Maria Augusta de; FERREIRA, Rejane Platero. O Museu das Culturas Dom Bosco: desenvolvimento local na educação básica. Campo Grande: Gráfica Mundial, 2012.

DESVALLÉES, André; MAIRESSE, François (Dir.). Conceitos-chave de Museologia. São Paulo: Comitê Brasileiro do ICOM, Pinacoteca do Estado, Secretaria de Estado da Cultura, 2013.

FERNANDES, Hélènemarie Dias. A (re)territorialização do patrimônio cultural tombado do Porto Geral de Corumbá-MS no contexto do desenvolvimento Local. 2009. 148 f. Dissertação (Mestrado em Desenvolvimento Local) - Universidade Católica Dom Bosco, Campo Grande, MS, 2009.

FONSECA, Selva Guimarães. Ser professor no Brasil: história oral de vida. Campinas, SP: Papirus, 1997.

FREIRE, Paulo. Pedagogia do oprimido. 32. ed. São Paulo: Paz e Terra, 2002.

FREIRE, Paulo. Pedagogia da indignação: cartas pedagógicas e outros escritos. São Paulo: UNESP, 2000.

FREIRE, Paulo. Educação e mudança. Rio de Janeiro: Paz e Terra, 1979.

GRINSPUN, Mirian P. S. Zippin. A orientação educacional: conflito de paradigmas e alternativas para a escola. São Paulo: Cortez, 2002.

HELLWIG, Alessandro Wickboldt. Museu, memória e identidade pomerana: uma correlação local. Expressa Extensão, Pelotas, RS, v. 19, n. 2, p. 1-14, 2014. Disponível em: https://periodicos.ufpel.edu.br/ojs2/index.php/expressaextensao/article/ view/4481/7891. Acesso em: 22 jul. 2019.

INSTITUTO BRASILEIRO DE MUSEUS (IBRAM). Museus e turismo: estratégias de Cooperação. Brasília: Ministério da Cultura/Instituto Brasileiro de Museus, 2014.

INSTITUTO BRASILEIRO DE MUSEUS (IBRAM). Mapa estratégico do IBRAM. [s.d.]. Disponível em: http://www.museus.gov.br/acessoainformacao/o-ibram. Acesso em: 18 ago. 2018. 
INSTITUTO DO PATRIMÔNIO HISTÓRICO E ARTÍSTICO NACIONAL (IPHAN). Caderno de diretrizes museológicas. 2. ed. Belo Horizonte: Secretaria de Estado da Cultura/ Superintendência de Museus, 2006.

LE GOFF, Jacques. História e memória. São Paulo: Editora da Unicamp, 1996.

LOPES, Maria Margaret. A favor da desescolarização dos museus. Educação \& Sociedade, Campinas, SP, n. 40, p. 443-55, 1991. Disponível em: https:// www.sisemsp.org.br/blog/wp-content/uploads/2016/04/A-favor-dadesescolariza\%C3\%A7\%C3\%A3o-dos-museus.pdf

LOURENÇO, Maria Cecília França. Museus à grande. Revista do Patrimônio Histórico e Artístico Nacional, Brasília, n. 30, p. 183-209, 2002.

MARANDINO, Martha. Interfaces na relação museu-escola. Caderno Brasileiro de Ensino de Física, Florianópolis, v. 18, n. 1, p. 85-100, abr. 2001.

MENESES, Ulpiano T. Bezerra. Do teatro da memória ao laboratório da História: a exposição museológica e o conhecimento histórico. Anais do Museu Paulista, São Paulo, N. Ser., v. 2, p. 9-42, jan./dez. 1994. Disponível em: http://www.scielo.br/ pdf/anaismp/v2n1/a02v2n1.pdf. Acesso em: 15 jun. 2017.

NORONHA, Elisa. Museus de Arte Contemporânea: uma estratégia de abordagem. Disponível em: http://interartive.org/2010/01/museucontemporaneo. Acesso em: 10 jun. 2017.

PADILHA, Renata Cardoso; CAFÉ, Lígia; SILVA, Edna Lúcia da. O papel das instituições museológicas na sociedade da informação/conhecimento. Perspectivas em Ciência da Informação, Belo Horizonte, v. 19, n. 2, p. 68-82, abr./jun., 2014.

POSSAS, Helga Cristina Gonçalves. Classificar e ordenar: os gabinetes de curiosidades e a história natural. In: FIGUEIREDO, Betânia Gonçalves; VIDAL, Diana Gonçalves (Org.). Museus: dos gabinetes de curiosidades a museologia moderna. 2. ed. Belo Horizonte: Fino Traço, 2013.

RAMOS, Francisco Regis Lopes. A danação do objeto. Chapecó, SC: Argos, 2004.

SUANO, Marlene. O que é museu? São Paulo: Brasiliense, 1986.

TODOROV, Tzvetan. Memória do mal, tentação do bem - indagações sobre o século XX. São Paulo: Arx, 2002. 